\section{Cutaneous manifestation of polycystic ovary syndrome}

Mohammad A. Abusailik, ${ }^{1}$ Alsharif M. Muhanna, ${ }^{1}$ Adam A. Almuhisen, ${ }^{1}$ Abdullah M. Alhasanat, ${ }^{1}$ Ayed M. Alshamaseen, ${ }^{2}$ Safa M. Bani Mustafa, ${ }^{1}$ Mohammed B. Nawaiseh ${ }^{3}$

${ }^{1}$ Department of Dermatology, Jordanian Royal Medical Services, Amman; ${ }^{2}$ Department of Obstetrics and Gynecology, Jordanian Royal Medical Services, Amman; ${ }^{3}$ Jordanian Royal Medical Services, Amman, Jordan

\section{Abstract}

The aim of this cross-sectional study, that included 146 polycystic ovary syndrome (PCOS) patients, was to evaluate the prevalence, severity and pattern of cutaneous manifestation in Jordanian women with PCOS, as well as their correlation with hormonal abnormalities. A thorough complete cutaneous examination, hormonal assays (Luteinizing hormone [LH], follicle stimulating hormone [FSH], prolactin, total testosterone, free testosterone, dehydroepiandrosterone sulfate) and pelvic ultrasonography were done. The most common cutaneous features of PCOS were acne vulgaris $(75.3 \%)$ followed by hirsutism $(59.6 \%)$ then seborrhea (43.2\%) and androgenetic alopecia (42.5\%). Patients who had acne vulgaris presented at a younger age than patients who did not. Patients who had androgenetic alopecia and stria were older than patients with no such features. Moreover, all cutaneous manifestations of PCOS, except for acne, were associated with higher body mass index (BMI). Elevated LH:FSH ratio of more than 2:1 was the most common hormonal abnormality, followed by increased $\mathrm{LH}$ and total testosterone. Acne, hirsutism, androgenetic alopecia, seborrhea, acanthosis nigricans and skin tags are common cutaneous manifestations among Jordanian patients with PCOS. The existence of one or more of these features, especially in overweight and obese patients, should alert the physician towards the possibility of having PCOS.

\section{Introduction}

Polycystic ovary syndrome (PCOS) is the most common endocrinopathy that affects women, with prevalence ranging from $6-10 \%$ among women in their repro- ductive years. $^{1-3}$ It is a multisystem metabolic disorder, with a significant impact on the quality of life as well as fertility. ${ }^{4,5}$

According to Rotterdam 2003 diagnostic criteria of PCOS, PCOS could be diagnosed if two of the following three criteria are present: 6

i. Oligoovulation and/or anovulation $(<8$ menses per $12 \geq$ month period).

ii. Hyperandrogenism (clinical or laboratory).

iii. Polycystic ovaries on ultrasound $(\geq 12$ follicles in each ovary measuring 2-9 $\mathrm{mm}$ in diameter and/or increased ovarian volume $>10 \mathrm{ml}$ ).

Cutaneous changes are one of the earliest manifestations of PCOS, which include acne, hirsutism, androgenetic alopecia (AGA), stria, acanthosis nigricans (AN) and skin tags. As part of a multidisciplinary approach to these patients, dermatologists also play a major role in its management.

A study by Gowri indicated that the prevalence of cutaneous manifestations of PCOS was nearly $90 \%$. $^{7}$ A number of studies have shown that acne was the most common dermatological manifestation followed by hirsutism, then seborrhea, then $\mathrm{AN}$ and AGA. ${ }^{7-10}$

Hirsutism, which is defined as excessive male pattern terminal, or coarse, hair growth in women, ${ }^{11}$ was found to have the greatest impact on the quality of life among women with PCOS. ${ }^{12}$ Acne was most often observed on the face and most acne lesions were distributed on the forehead followed by cheek, chin, and nose. ${ }^{9,10}$ There is a strong correlation between acne and PCOS, as most women $(83 \%)$ with acne had polycystic ovaries. ${ }^{13}$ Hirsutism, acne vulgaris, and AGA are signs of hyperandrogenism, while AN is a cutaneous sign of hyperinsulinemia. Acne and androgenic alopecia are considered less reliable markers for hyperandrogenism than hirsutism. ${ }^{8,14,15}$

PCOS cutaneous features may differ in various ethnic groups. ${ }^{16,17}$ In the Arab region, there is limited research about the dermatological manifestations of PCOS and to the best of our knowledge, there are no studies evaluating the cutaneous manifestations of PCOS among Jordanian women.

This study was carried out to identify the prevalence and pattern of cutaneous manifestations in Jordanian patients with PCOS, as well as their correlation with hormonal abnormalities.

\section{Materials and Methods}

This is a multicenter cross-sectional
Correspondence: Mohammed Bassam Nawaiseh, Jordanian Royal Medical Services, Amman, Jubaiha 11941, Amman, Jordan.

Tel: +962.797750246 .

E-mail: mohammednawaiseh.md@gmail.com

Key words: Polycystic ovary syndrome, Acne, Hirsutism, Androgenetic alopecia, Acanthosis nigricans.

Contributions: The authors contributed equally.

Conflict of interest: The authors declare no potential conflict of interest.

Funding: None.

Ethical approval: Institutional ethical approval was obtained from the Jordanian Royal Medical Services (JRMS) ethical committee (Approval \# 3/2019).

Data availability: The dataset analyzed during the current study are available from the corresponding author upon reasonable request.

Please cite this article as: Abusailik MA, Muhanna AM, Almuhisen AA, et al. Cutaneous manifestation of polycystic ovary syndrome. Dermatol Rep 2021;13:8799.

Received for publication: 17 July 2020. Revision received: 18 March 2021. Accepted for publication: 25 March 2021.

This work is licensed under a Creative Commons Attribution-NonCommercial 4.0 International License (CC BY-NC 4.0).

(C) Copyright: the Author(s), 2021

Licensee PAGEPress, Italy

Dermatology Reports 2021; 13:8799

doi:10.4081/dr.2021.8799

study that was approved by the Jordanian Royal Medical Services (JRMS) ethical committee. One hundred and forty-six patients attended the dermatology outpatient clinics in five hospitals of JRMS in the period between September 2018 and November 2019 fulfilling the eligibility criteria were included in the study and examined for the presence of cutaneous manifestations.

For each patient to be included in the study, the patient must fulfill the following inclusion criteria:

i. Meeting Rotterdam 2003 diagnostic criteria of PCOS.6

ii. Age between 18 to 40 years.

iii. Willing to participate in the study.

Patients were excluded according to the following exclusion criteria:

i. Being a pregnant or breastfeeding woman. 
ii. Presence of other associated comorbidities that lead to hormonal imbalance such as ovarian or adrenal neoplasm.

iii. Taking hormonal therapy such as oral contraceptives or antiandrogens.

Written informed consent had been obtained from all of the participants, after which a detailed dermatological history and examination were elicited in each case. Height and weight of each patient were recorded to calculate the body mass index (BMI).

Hormonal profile was done on the second day of spontaneous menstruation including follicle stimulating hormone (FSH), luteinizing hormone ( $\mathrm{LH})$, total and free testosterone, dehydroepiandrosterone sulfate (DHEA-S) and prolactin. LH/FSH ratio of more than two was considered abnormal. Abdominal ultrasonography was done as part of the diagnostic criteria for PCOS.

Since there is no universally accepted grading system, we graded acne as comedonal, papulopustular or nodulocystic. According to Hayashi et al., papulopustular acne was further sub classified based on the number of inflammatory eruptions as mild (0-5), moderate (6-20), severe (21-50), and very severe (more than 50 ). ${ }^{18}$

Women with hirsutism were assessed according to Ferriman-Gallwey score. ${ }^{19}$ The terminal hair density at 11 different body sites (lip, chin, chest, upper abdomen, lower abdomen, upper arm, forearm, thigh, lower leg, upper back, and lower back) were scored from zero (no excess hair growth) up to four (densely distributed hair), and a total score was calculated by summing the score of each body site. A score of eight or more was considered diagnostic of hirsutism.

AGA was assessed according to Sinclair scale for female pattern hair loss. Stage 1 is considered normal, stage 2 shows widening of the central part, stage 3 shows widening of the central part and loss of volume lateral to the part line, stage 4 shows the development of a bald spot anteriorly and stage 5 shows advanced hair loss. ${ }^{20}$

Seborrhea was clinically diagnosed by detecting dry, flaking scales on the scalp (dandruff or pityriasis simplex capiliti) or erythematous patches with yellow-gray scales that most commonly appear on the face, scalp, upper chest, and back (seborrheic dermatitis). ${ }^{21}$ The diagnosis of AN was done clinically by observation of dark, coarse and thickened skin with a velvety texture, being symmetrically distributed on the neck, the axillae, antecubital and popliteal fossae and groin folds. ${ }^{22}$ Skin tags and stria were clinically diagnosed through cutaneous examination.

\section{Statistical analysis}

Data were analyzed using SPSS version 25. Age was expressed as mean \pm standard deviation (SD) and other categorical data by frequency and percentage (Table 1). All statistical tests were twosided and $\mathrm{P}$-values $<0.05$ were considered statistically significant. As age was normally distributed, we used independent samples t-test to assess if there was a difference in age among different cutaneous PCOS manifestations (Table 2). Hormonal levels were not normally distributed, thus Kruskal-Wallis test was used to assess the difference in hormonal profile between acne types, AGA stages, and seborrheic dermatitis severity. Table 3 includes details regarding the hormonal profile for the patients included in this study. Moreover, chi square test was used to compare the presence or absence of cutaneous features between normal weight (BMI $<25 \mathrm{~kg} / \mathrm{m} 2$ ) group and overweight-obese (BMI $\geq 25$ $\mathrm{kg} / \mathrm{m}^{2}$ ) group (Table 4), compare the number of patients having four or more cutaneous features among each cutaneous PCOS characteristic (Table 5), examine if there is an association between acne and seborrhea, and assess the difference between specific cutaneous manifestation and having high hormone levels (Table 6).

Table 1. Prevalence and detailed characteristics of the PCOS cutaneous manifestations.

\begin{tabular}{|c|c|c|}
\hline Cutaneous manifestation & Details & Number $(\%)$ \\
\hline Acne vulgaris & $\begin{array}{l}\text { Comedonal acne } \\
\text { Mild papulopustular acne } \\
\text { Moderate papulopustular acne } \\
\text { Severe papulopustular acne } \\
\text { Very severe papulopustular acne } \\
\text { Nodulocystic acne } \\
\text { Total }\end{array}$ & $\begin{array}{c}36(32.7) \\
16(14.6) \\
21(19.1) \\
16(14.6) \\
9(8.1) \\
12(10.9) \\
110(75.3)\end{array}$ \\
\hline Hirsutism & $\begin{array}{l}8-14 \\
\geq 15 \\
\text { Total }\end{array}$ & $\begin{array}{l}61(70.1) \\
26(29.9) \\
87(59.6)\end{array}$ \\
\hline Seborrhea & $\begin{array}{l}\text { Dandruff (pityriasis simplex capiliti) } \\
\text { Mild seborrheic dermatitis } \\
\text { Severe seborrheic dermatitis } \\
\text { Total }\end{array}$ & $\begin{aligned} & 34(54) \\
27 & (42.9) \\
2 & (3.1) \\
63 & (43.2)\end{aligned}$ \\
\hline Androgenetic alopecia & $\begin{array}{l}\text { Widening of the central part (Stage 2) } \\
\text { Widening of the central part and loss of volume lateral to the part line (Stage 3) } \\
\text { Bald spot anteriorly (Stage 4) } \\
\text { Advanced hair loss (Stage 5) } \\
\text { Total }\end{array}$ & $\begin{array}{l}23(37.1) \\
17(27.4) \\
15(24.2) \\
7(11.3) \\
62(42.5)\end{array}$ \\
\hline $\begin{array}{l}\text { Stria } \\
\text { Acanthosis nigricans } \\
\text { Skin tags } \\
\text { Presenting feature }\end{array}$ & $\begin{array}{l}\text { Total } \\
\text { Total } \\
\text { Total } \\
\text { No presenting feature } \\
\text { Hirsutism } \\
\text { Acne } \\
\text { Androgenetic alopecia } \\
\text { Stria } \\
\text { Acanthosis nigricans }\end{array}$ & $\begin{array}{l}52(35.6) \\
46(31.5) \\
23(15.8) \\
27(18.5) \\
63(43.2) \\
36(24.7) \\
15(10.3) \\
4(2.7) \\
1(0.7)\end{array}$ \\
\hline
\end{tabular}




\section{Results}

A total of 146 Jordanian female patients diagnosed to have PCOS were included in this study and subjected to final analysis. The mean age was $26.3 \pm 4.6$ years, the youngest patient was 18 years old and the oldest patient was 40 years old. The mean BMI was $25.9 \pm 3.8 \mathrm{~kg} / \mathrm{m}^{2}$, with about half of the patients being normal or underweight (74 patients, $50.7 \%$ ). The most common cutaneous manifestation of PCOS among the patients in our study were acne vulgaris $(\mathrm{n}=110,75.3 \%)$, followed by hirsutism $(n=87,59.6 \%)$, then seborrhea $(n=63$, $43.2 \%), \operatorname{AGA}(n=62,42.5 \%)$ and stria $(\mathrm{n}=52,35.6 \%)$. The least common cutaneous features were AN ( $\mathrm{n}=46,31.5 \%)$ and skin tags $(n=23,15.8 \%)$. The most common presenting symptoms were hirsutism $(\mathrm{n}=63$, $43.2 \%)$ followed by acne $(n=36,24.7 \%)$. Twenty-seven patients $(18.5 \%)$ were referred to the dermatology clinic or presented for other complaints not related to PCOS (Table 1).

The most common sites of acne were chin $(n=65)$, jawline $(n=57)$, cheek $(n=54)$, trunk $(n=38)$, forehead $(n=37)$, nose $(n=30)$ and lip $(n=25)$. The most common sites of hirsutism were chin $(n=50)$, thigh $(n=47)$, lip $(n=42)$ and upper chest $(n=38)$. The most common sites of AN and skin tags were the neck and axilla.

We noted that patients who suffered from acne were younger than patients who did not (Mean differences $[\mathrm{MD}]=4.9$ years, $\mathrm{p}<0.001)$. Moreover, patients who had AGA $(\mathrm{MD}=-6.4$ years, $\mathrm{p}<0.001)$ and stria $(\mathrm{MD}=$ -2.1 years, $p=0.008$ ) were older than patients who had no such features. More details can be found in Table 2 .

Patients who had abnormal BMI (overweight or obese) were more likely to present with cutaneous manifestation of PCOS than patients with normal BMI (Table 4). One exception was acne vulgaris, where there was no significant difference $(p=0.149)$ in acne prevalence between patients with normal (47.3\%) and abnormal (52.7\%) BMI groups. All patients who had skin tags or AN were either overweight or obese $(\mathrm{p}<0.001)$. Only two patients with stria had a normal BMI $(\mathrm{p}<0.001)$. Patients who had abnormal BMI were more likely to have hirsutism $(60.9 \%, \mathrm{p}=0.001)$, seborrhea (63.5\%, $\mathrm{p}=0.003)$, and AGA (66.1\%, $\mathrm{p}<0.001$ ) than patients with normal BMI.
We found no significant association between acne and seborrhea, X2 $=0.353$, $\mathrm{p}=0.551$. Although, not statistically significant $(\mathrm{X} 2=5.14, \mathrm{p}=0.076)$, we found that patients with nodulocystic acne $(\mathrm{N}=9$, $75.0 \%$ ) had seborrhea, compared to only three patients $(25 \%)$ with no seborrhea. Patients with papulopustular and comedonal acne had seborrhea in $41.9 \%$ and $38.8 \%$ of cases.

Patients with either one of the following features; stria (96.2\%), skin tags $(95.7 \%)$, AN (93.5\%), seborrhea (66.7\%), AGA $(64.5 \%)$, and hirsutism $(62.1 \%)$ were more likely to have four or more PCOS features $(\mathrm{p}<0.001)$ than patients with no such features, with a very strong correlation (phi $>0.25$ ). This implies that these skin characteristics were more likely to show up collectively (Table 5).

Regarding laboratory abnormalities, elevated LH:FSH ratio of more than $2: 1$ was the most common hormonal abnormality in our patients, followed by increased LH and total testosterone (Table 3). Thirty eight percent $(38.4 \%)$ of our patients had normal hormonal profiles, while the rest $(61.6 \%)$ presented with one or more hormonal abnormalities (including abnormal

Table 2. Age differences among PCOS cutaneous manifestations.

\begin{tabular}{|c|c|c|c|c|c|}
\hline Manifestation & & Mean age in years (SD) & MD & P-value & $95 \% \mathrm{CI}$ \\
\hline Acne vulgaris & $\begin{array}{l}\text { Without } \\
\text { With }\end{array}$ & $\begin{array}{l}30.1(4.5) \\
25.1(4.0)\end{array}$ & 4.9 & $<0.001$ & $(3.4,6.5)$ \\
\hline Hirsutism & $\begin{array}{l}\text { Without } \\
\text { With }\end{array}$ & $\begin{array}{l}26.0(5.0) \\
26.5(4.4)\end{array}$ & -0.5 & 0.507 & $(-2.0,1.0)$ \\
\hline Seborrhea & $\begin{array}{l}\text { Without } \\
\text { With }\end{array}$ & $\begin{array}{l}26.3(4.8) \\
26.4(4.4)\end{array}$ & -0.1 & 0.911 & $(-1.6,1.4)$ \\
\hline Androgenetic Alopecia & $\begin{array}{l}\text { Without } \\
\text { With }\end{array}$ & $\begin{array}{l}23.6(2.8) \\
30.0(4.0)\end{array}$ & -6.4 & $<0.001$ & $(-7.5,-5.3)$ \\
\hline Stria & $\begin{array}{l}\text { Without } \\
\text { With }\end{array}$ & $\begin{array}{l}25.6(4.5) \\
27.7(4.6)\end{array}$ & -2.1 & 0.008 & $(-3.6,-.5)$ \\
\hline Acanthosis nigricans & $\begin{array}{l}\text { Without } \\
\text { With }\end{array}$ & $\begin{array}{l}26.0(4.7) \\
27.0(4.3)\end{array}$ & -1.1 & 0.204 & $(-2.6,0.5)$ \\
\hline Skin tags & $\begin{array}{l}\text { Without } \\
\text { With }\end{array}$ & $\begin{array}{l}26.2(4.9) \\
27.1(3.0)\end{array}$ & -0.9 & 0.365 & $(-3.0,1.1)$ \\
\hline
\end{tabular}

SD, Standard Deviation; MD, Mean Difference; CI, Confidence Interval.

Table 3. Hormonal profile for the patients in our study.

\begin{tabular}{lccc} 
& Normal value & Median (IQR) & Number of abnomally high level (\%) \\
LH & $(2.4$ to 12.6$) \mathrm{IU} / \mathrm{L}$ & $10.2(3.3)$ & $34(23.3)$ \\
FSH & $(3.5$ to 12.5$) \mathrm{IU} / \mathrm{L}$ & $5.9(2.3)$ & $4(2.7)$ \\
\hline LH/FSH Ratio & $<2$ & $1.7(1.3)$ & $65(44.5)$ \\
Total testosterone & $(8.4$ to 48.1$) \mathrm{ng} / \mathrm{dl}$ & $26.0(14.0)$ & $28(19.2)$ \\
\hline Free testosterone & $(0.3-2) \mathrm{pg} / \mathrm{ml}$ & $0.8(0.7)$ & $4(2.7)$ \\
Dehydroepiandrosterone (DHEA-S) & $(145$ to 395$) \mu \mathrm{g} / \mathrm{dL}$ & $250.5(106.0)$ & $3(2.1)$ \\
\hline Prolactin & $(8.4$ to 23.3$) \mathrm{ng} / \mathrm{ml}$ & $15.1(10.0)$ & $8(5.5)$ \\
\hline
\end{tabular}

$\mathrm{IQR}$, Interquartile range. 
LH:FSH ratio). Patients who had one abnormal hormonal level were $52(35.6 \%)$, and two or more abnormal hormonal levels were $28(26.1 \%)$.

Patients with acne (23.6\%) were more likely to have abnormally high total testosterone level than patients with no acne (5.6\%), $\mathrm{p}=0.026$. AN was associated with having abnormally high LH levels $(\mathrm{p}=0.003)$ and $\mathrm{LH} / \mathrm{FSH}$ ratio $(\mathrm{p}=0.021)$. The absence of AGA was associated with higher total testosterone $(p=0.018)$. Skin tags were associated with having abnormally high LH levels $(\mathrm{p}=0.017)$. Seborrhea was associated with higher free testosterone $(\mathrm{p}=0.033)$.

Total testosterone level was statistically higher in Nodulocystic Acne (mean rank =
Table 4. The prevalence of cutaneous features among different BMI groups.

\begin{tabular}{lccc} 
& BVII group & N (\%) & P-value \\
Acne vulgaris & $\leq 24.9$ & $52(47.3)$ & 0.149 \\
& $\geq 25$ & $58(52.7)$ & \\
Hirsutism & $\leq 24.9$ & $34(39.1)$ & 0.001 \\
& $\geq 25$ & $53(60.9)$ & \\
Seborrhea & $\leq 24.9$ & $23(36.5)$ & 0.003 \\
& $\geq 25$ & $40(63.5)$ & \\
Androgenetic alopecia & $\leq 24.9$ & $21(33.9)$ & $<0.001$ \\
& $\geq 25$ & $41(66.1)$ & $<0.001$ \\
Stria & $\leq 24.9$ & $2(3.8)$ & $<0.001$ \\
& $\geq 25$ & $50(96.2)$ & \\
Acanthosis nigricans & $\leq 24.9$ & $0(0.0)$ & $<0.001$ \\
& $\geq 25$ & $46(100.0)$ & \\
\hline Skin tags & $\leq 24.9$ & $0(0.0)$ & \\
& $\geq 25$ & $23(100.0)$ & \\
\hline
\end{tabular}

Table 5. Chi square to compare the number of patients having four or more cutaneous features among each cutaneous PCOS characteristic

\begin{tabular}{|c|c|c|c|c|}
\hline Variables & & 4 or more cutaneous features & P-value & Phi correlation \\
\hline Acne & $\begin{array}{l}\text { Without } \\
\text { With }\end{array}$ & $\begin{array}{l}12(33.3) \\
56(50.9)\end{array}$ & 0.084 & 0.151 \\
\hline Hirsutism & $\begin{array}{l}\text { Without } \\
\text { With }\end{array}$ & $\begin{array}{l}14(23.7) \\
54(62.1)\end{array}$ & $<0.001$ & 0.377 \\
\hline Acanthosis nigricans & $\begin{array}{l}\text { Without } \\
\text { With }\end{array}$ & $\begin{array}{l}25(25.0) \\
43(93.5)\end{array}$ & $<0.001$ & 0.638 \\
\hline Androgenetic alopecia & $\begin{array}{l}\text { Without } \\
\text { With }\end{array}$ & $\begin{array}{l}28(33.3) \\
40(64.5)\end{array}$ & $<0.001$ & 0.309 \\
\hline Stria & $\begin{array}{l}\text { Without } \\
\text { With }\end{array}$ & $\begin{array}{l}18(19.1) \\
50(96.2)\end{array}$ & $<0.001$ & 0.739 \\
\hline Skin tags & $\begin{array}{l}\text { Without } \\
\text { With }\end{array}$ & $\begin{array}{l}46(37.4) \\
22(95.7)\end{array}$ & $<0.001$ & 0.425 \\
\hline Seborrhea & $\begin{array}{l}\text { Without } \\
\text { With }\end{array}$ & $\begin{array}{l}26(31.3) \\
42(66.7)\end{array}$ & $<0.001$ & 0.351 \\
\hline
\end{tabular}

Table 6. Chi square to test the difference in abnormally high hormonal levels among different PCOS cutaneous manifestations.

\begin{tabular}{|c|c|c|c|c|c|c|c|c|}
\hline & & $\begin{array}{l}\text { High } \\
\text { LH }\end{array}$ & $\begin{array}{l}\text { High } \\
\text { FSH }\end{array}$ & $\begin{array}{c}\text { High } \\
\text { LH/FSH }\end{array}$ & $\begin{array}{l}\text { High } \\
\text { Prolactin }\end{array}$ & $\begin{array}{l}\text { High Total } \\
\text { Testosterone }\end{array}$ & $\begin{array}{l}\text { High Free } \\
\text { Testosterone }\end{array}$ & DHEAs \\
\hline Acne & $\begin{array}{l}\text { Absent } \\
\text { Present } \\
\text { P-value }\end{array}$ & $\begin{array}{c}10(27.8) \\
24(21.8) \\
0.499\end{array}$ & $\begin{array}{c}1(2.8) \\
3(2.7) \\
1.000\end{array}$ & $\begin{array}{c}19(52.8) \\
46(41.8) \\
0.334\end{array}$ & $\begin{array}{c}2(5.6) \\
6(5.5) \\
1.000\end{array}$ & $\begin{array}{c}2(5.6) \\
26(23.6) \\
0.026\end{array}$ & $\begin{array}{c}0(0.0) \\
4(3.6) \\
0.572\end{array}$ & $\begin{array}{c}1(2.8) \\
2(1.8) \\
1.000\end{array}$ \\
\hline Hirsutism & $\begin{array}{l}\text { Absent } \\
\text { Present } \\
\text { P-value }\end{array}$ & $\begin{array}{c}12(20.3) \\
22(25.3) \\
0.553\end{array}$ & $\begin{array}{c}2(3.4) \\
2(2.3) \\
1.000\end{array}$ & $\begin{array}{c}21(35.6) \\
44(50.6) \\
0.090\end{array}$ & $\begin{array}{c}2(3.4) \\
6(6.9) \\
0.474\end{array}$ & $\begin{array}{c}10(16.9) \\
18(20.7) \\
0.671\end{array}$ & $\begin{array}{c}1(1.7) \\
3(3.4) \\
0.648\end{array}$ & $\begin{array}{c}0(0.0) \\
3(3.4) \\
0.273\end{array}$ \\
\hline Acanthosis nigricans & $\begin{array}{l}\text { Absent } \\
\text { Present } \\
\text { P-value }\end{array}$ & $\begin{array}{c}16(16.0) \\
18(39.1) \\
0.003\end{array}$ & $\begin{array}{c}3(3.0) \\
1(2.2) \\
1.000\end{array}$ & $\begin{array}{c}38(38.0) \\
27(58.7) \\
0.021\end{array}$ & $\begin{array}{c}5(5.0) \\
3(6.5) \\
1.000\end{array}$ & $\begin{array}{c}16(16.0) \\
12(26.1) \\
0.177\end{array}$ & $\begin{array}{c}1(1.0) \\
3(6.5) \\
0.093\end{array}$ & $\begin{array}{c}3(3.0) \\
0(0.0) \\
0.552\end{array}$ \\
\hline Androgenetic alopecia & $\begin{array}{l}\text { Absent } \\
\text { Present } \\
\text { P-value }\end{array}$ & $\begin{array}{c}17(20.2) \\
17(27.4) \\
0.328\end{array}$ & $\begin{array}{c}2(2.4) \\
2(3.2) \\
1.000\end{array}$ & $\begin{array}{c}35(41.7) \\
30(48.4) \\
0.501\end{array}$ & $\begin{array}{c}3(3.6) \\
5(8.1) \\
0.285\end{array}$ & $\begin{array}{c}22(26.2) \\
6(9.7) \\
0.018\end{array}$ & $\begin{array}{c}3(3.6) \\
1(1.6) \\
0.637\end{array}$ & $\begin{array}{c}3(3.6) \\
0(0.0) \\
0.262\end{array}$ \\
\hline Stria & $\begin{array}{l}\text { Absent } \\
\text { Present } \\
\text { P-value }\end{array}$ & $\begin{array}{c}19(20.2) \\
15(28.8) \\
0.307\end{array}$ & $\begin{array}{c}2(2.1) \\
2(3.8) \\
0.616\end{array}$ & $\begin{array}{c}36(38.3) \\
29(55.8) \\
0.056\end{array}$ & $\begin{array}{c}4(4.3) \\
4(7.7) \\
0.456\end{array}$ & $\begin{array}{c}15(16.0) \\
13(25.0) \\
0.195\end{array}$ & $\begin{array}{c}1(1.1) \\
3(5.8) \\
0.129\end{array}$ & $\begin{array}{c}3(3.2) \\
0(0.0) \\
0.307\end{array}$ \\
\hline Skin tags & $\begin{array}{l}\text { Absent } \\
\text { Present } \\
\text { P-value }\end{array}$ & $\begin{array}{c}24(19.5) \\
10(43.5) \\
0.017\end{array}$ & $\begin{array}{c}3(2.4) \\
1(4.3) \\
1.000\end{array}$ & $\begin{array}{c}51(41.5) \\
14(60.9) \\
0.110\end{array}$ & $\begin{array}{c}7(5.7) \\
1(4.3) \\
1.000\end{array}$ & $\begin{array}{c}23(18.7) \\
5(21.7) \\
0.774\end{array}$ & $\begin{array}{c}3(2.4) \\
1(4.3) \\
1.000\end{array}$ & $\begin{array}{c}3(2.4) \\
0(0.0) \\
1.000\end{array}$ \\
\hline Seborrhea & $\begin{array}{l}\text { Absent } \\
\text { Present } \\
\text { P-value }\end{array}$ & $\begin{array}{c}20(24.1) \\
14(22.2) \\
0.845\end{array}$ & $\begin{array}{c}1(1.2) \\
3(4.8) \\
0.315\end{array}$ & $\begin{array}{c}34(41.0) \\
31(49.2) \\
0.401\end{array}$ & $\begin{array}{c}4(4.8) \\
4(6.3) \\
0.726\end{array}$ & $\begin{array}{c}11(13.3) \\
17(27.0) \\
0.055\end{array}$ & $\begin{array}{c}0(0.0) \\
4(6.3) \\
0.033\end{array}$ & $\begin{array}{c}3(3.6) \\
0(0.0) \\
0.259\end{array}$ \\
\hline
\end{tabular}

P value is two sided, \# number. 
124.2) than in Papulopustular (mean rank = 74.9) or Comedonal (mean rank $=60.4$ ) acne types, $X^{2}=21.7, p<0.001$. There was no statistically significant difference in hormonal levels between different AGA stages. Severe seborrheic dermatitis (mean rank $=$ 145.5) was associated with higher $(\mathrm{p}=0.043$ ) free testosterone levels than mild seborrheic dermatitis (mean rank $=73.5$ ) and dandruf (mean rank $=81.2$ ).

\section{Discussion}

Cutaneous manifestations of PCOS occur early in the course of the disease and play a role in diagnosis and in the therapeutic options. The vast majority of PCOS patients have attended or been referred to the dermatology clinics seeking management of these cutaneous manifestations. PCOS and its cutaneous features in particular affect the quality of life and the psychological well-being. ${ }^{23}$ Therefore, we conducted this study to assess the prevalence, severity and characteristics of these cutaneous manifestations in Jordanian patients, in order to achieve careful assessment, timely and appropriate management, and reduction in psychological burden of PCOS.

In our study we found that patients with AGA and stria were older than patients who had no such features. Moreover, patients who had abnormal BMI (overweight or obese) were more likely to present with cutaneous manifestation of PCOS, except for acne, than patients with normal BMI. Patients having either of the cutaneous features, except for acne, were more likely to have four or more PCOS cutaneous manifestations, especially AN or stria or skin tags, as more than $90 \%$ of patients who have these features have multiple manifestations.

A number of studies have shown that acne was the most common PCOS dermatological manifestation, followed by hirsutism, seborrhea, AN and AGA which is concordant with the results of our study. ${ }^{8-10}$ Gowri found that the prevalence of cutaneous manifestations of PCOS was nearly $90 \%$, in our study all the patients were affected by at least one cutaneous feature. ${ }^{7}$

In our study, acne vulgaris was the most common cutaneous feature of PCOS, affecting three quarters of the patients $(75.3 \%)$, which is slightly higher but consistent with the findings from other studies, in which the prevalence of acne among PCOS patients was between $57 \%$ and $67.5 \% .^{7,24-27}$ Although acne was the most common feature, it was the second presenting symptom. The distribution of acne lesions is similar to acne patients in the general population and in hirsute patients, ${ }^{28,29}$ affecting most commonly the chin, jawlines, cheeks, and trunk. Acne presents usually in adolescent and young adults, ${ }^{30}$ that is also true for PCOS patients who had acne as they were younger than patients who had not. Acne in PCOS patients tends to be more severe, and resistant to the available therapeutic options, $33.6 \%$ of acne patients in our study had severe acne, while only $15 \%$ of Jordanian acne patients had severe acne. ${ }^{31}$ Acne was the only cutaneous feature of PCOS which was not associated with being overweight or obese, also it was the only feature that did not tend to occur with other features. Thus, acne may be the only presenting cutaneous feature of PCOS. Therefore, all women with acne should be suspected to have PCOS and asked about their menstrual patterns. Those who have menstrual disturbances should have hormonal profile and pelvic ultrasound for ovarian visualization.

PCOS is the most common cause of hirsutism, it is responsible for nearly $70 \%$ of hirsutism cases, followed by idiopathic hirsutism (20\%). ${ }^{32}$ Moreover, it is considered to be the earliest cutaneous feature in PCOS. ${ }^{33}$ In the Arab world, PCOS was the commonest cause of hirsutism (91\%, 82\% and $72.6 \%$ ) among women in the United Arab of Emirates, Saudi Arabia and Lebanon, respectively. ${ }^{34-36}$ The frequency of hirsutism in our study was $59.6 \%$, this result was higher than other studies from USA with a prevalence of $43.9 \%,{ }^{25}$ India with a prevalence of $47.1 \%,{ }^{27}$ but was much lower than the what was reported in other arabic countries and in a study done by Saxena et al., in which the prevalence of hirsutism in lean PCOS patients was $81 \%$ and in overweight PCOS patients was $89 \% .{ }^{37}$ The prevalence of hirsutism among PCOS patients in these studies is generally above $40 \%$, which is much higher than the $5 \%-10 \%$ prevalence of hirsutism in women of childbearing age. ${ }^{38-40}$ Hirsutism was the most common presenting complaint and reported by our patients to be the most worrying feature that brings them to seek medical consultation, especially in women from rural areas in Jordan; this is most likely due to the social stigma of hirsutism, and lack of hair removal laser clinics.

AGA results from the conversion of scalp terminal hairs into smaller vellus hairs in a characteristic pattern. ${ }^{41}$ The prevalence of AGA in our study was $42.5 \%$ while the prevalence of AGA in the general population of women under the age of 50 is only $6 \%{ }^{42}$ This significant difference confirms the role of metabolic derangement of PCOS in the pathogenesis of androgenetic alopecia. Our result was slightly higher than those reported in previous studies with prevalences between $31 \%$ and $35 \% .{ }^{43,44}$ The age difference was statistically significant between PCOS patients with and without AGA ( 30 years vs 23.6 years, respectively), this is consistent with different studies that were reviewed by Ramos et al., which stated that AGA increases with age and has a slow and progressive course. ${ }^{45}$ Only $10 \%$ of patients presented were concerned about androgenetic alopecia, this might be because most of our patients wear a veil (Islamic hijab) that mask this symptom when they socialize with other people, and because most of our patients had AGA stage 2 and $3(64.5 \%)$ that might be unnoticeable by others.

Seborrhea was present in $43.2 \%$ of PCOS patients, mostly in the form of dandruff and mild seborrheic dermatitis. Only two cases had widespread severe seborrheic dermatitis. Similar prevalence $(41.9 \%)$ was found by Jain et al., ${ }^{26}$ but the prevalence in our study was higher than the prevalence found in other studies $(21.42 \%, 29 \%$, and $34.7 \%)^{27,43-45}$

AN was observed in $31.5 \%$ of our PCOS patients. All PCOS patients with AN were either overweight or obese, which is predictable because this dermatosis is weight dependent, and lesions may completely regress with weight reduction..$^{46,47}$ Our study results are consistent with studies done by Yerram et al. and Jain et al. who found similar results, $34.2 \%$ and $35.3 \%$, respectively. ${ }^{26,27}$ Shivaprakash et al. ${ }^{48}$ found a higher prevalence of AN in PCOS patients (56\%). Higher prevalence of AN (69\%) was found by Sharquie et al. in the neighboring country Iraq. ${ }^{49}$ They included only infertile women who were suspected to have higher BMI and greater hormonal, biochemical and metabolic abnormalities, this would explain the high incidence of AN in this study.

Obesity (BMI $\geq 30$ ) and overweight (BMI 25-29.9) presented in $49.2 \%$ of patients, which is lower than $58 \%$ and $62.8 \%$ found in other studies. ${ }^{27,37}$ A systematic review that included 106 studies concluded that women with PCOS had a greater risk of being overweight or obese. ${ }^{50}$ Additionally, we found a statistically significant association between all cutaneous features of PCOS (except for acne) and BMI, as patients with higher BMI, had more cutaneous features of PCOS. Obesity is associated with relative functional hyperandrogenism that is associated with increased testosterone level in PCOS patients. . $^{51,52}$

Stria and skin tags presented in $35.6 \%$ and $15.8 \%$ respectively, and occurred almost exclusively in obese and overweight patients. Yerram et al. found higher preva- 
lence of stria $(48.5 \%)$ and similar prevalence of skin tags $(17.14 \%))^{27}$ Jain et al. found a lower prevalence of skin tags $(11.8 \%){ }^{26}$

After a thorough investigation of the literature on hormonal abnormalities and correlation between these abnormalities and cutaneous manifestation of PCOS, we found equivocal and varied results. The factors that play a role in this variation are different genetic architectures and PCOS phenotypes, ethnicity and different available hormonal assays. ${ }^{16,17,53,54}$ In our study, the most common hormonal abnormality was elevated LH:FSH ratio (44.5\%), followed by increased LH level (34\%) and elevated total testosterone $(28 \%)$. Similar to our study, Jain et al. and Keen et al. found elevated LH:FSH ratio to be the most frequent hormonal abnormality, occurring at comparable percentages $(45 \%$ and $38 \%$, respectively), followed by elevated total testosterone (35\% and $28 \%$, respectively) and increased LH level $(21 \%$ and $16 \%$, respectively). ${ }^{26,44}$ On the other hand, Gowri found that elevated total testosterone level to be the most frequent hormonal abnormality (55\%), followed by increased $\mathrm{LH}$ ratio (35\%) which is similar to the results of our study. However the percentage of increased LH:FSH ratio (27.5\%) was lower than what found in our study. ${ }^{7}$ About $38 \%$ of PCOS patients in our study have normal hormonal profile, this finding confirms that hormonal abnormalities is not a prerequisite for the diagnosis of PCOS. ${ }^{6}$

In this study, certain cutaneous features were associated with specific laboratory abnormalities (Table 6). Acne was associated with higher total testosterone levels. Comedonal and papulopustular acne were associated with slightly lower biochemical hyperandrogenemia than nodulocystic acne, which has statistically significant association with elevated total testosterone level. Moreover, Franik et al. found that the severity of acne was correlated only with higher dehydroepiandrosterone sulfate (DHEA-s) concentration; other androgens did not affect the severity. ${ }^{55}$ Conversely, another study indicated that acne was unreliable marker of biochemical hyperandrogenism. ${ }^{25}$ In this study, although there was no statistically significant association between hirsutism and laboratory hyperandrogenemia or other laboratory abnormalities, hirsutism is considered by other researchers as a reliable marker for clinical hyperandrogenism. ${ }^{8,14,15}$ In accordance with Cela et al., AGA was associated with high total testosterone level. In contrast, Quinn did not find any association between biochemical hyperandrogenemia and AGA. ${ }^{56,57} \mathrm{AN}$ was associated with high $\mathrm{LH}$ and increased
LH:FSH ratio. Timothy reported an association between AN and elevated free testosterone level and concluded that $\mathrm{AN}$ is a marker of biochemical hyperandrogenism and warrants further diagnostic evaluation for metabolic co-morbidities that may lead to long term complication. ${ }^{25}$

The findings of this study have to be seen in the light of some limitations. The first includes the effect of previous or current therapies (e.g. topical and systemic acne therapy, topical minoxidil, hair reducing therapy and weight control measures) on the clinical presentation, which could not be minimized. Additionally, as with all cross-sectional studies which provide only a view at single point in time: these findings might differ if another time interval had been used.

\section{Conclusions}

PCOS is a disease of childbearing age females, which has various cutaneous presentations. Acne, hirsutism, AGA, seborrhea, AN, skin tags and stria have strong association with PCOS. The existence of one or more of these cutaneous features, especially in overweight and obese patients, should alert the physician towards the possibility of having PCOS. A multidisciplinary approach should be followed in dealing with a case of PCOS with involvement of a gynecologist, dermatologist, endocrinologist, psychiatrics and nutritionist in order to put a proper management plan and reduce the physical and psychological burden of the disease.

\section{References}

1. Goodarzi MO, Azziz R. Diagnosis, epidemiology, and genetics of the polycystic ovary syndrome. Best Pract Res Clin Endocrinol Metab 2006;20:193-205.

2. Nidhi R, Padmalatha V, Nagarathna R, Amritanshu R. Prevalence of polycystic ovarian syndrome in Indian adolescents. J Pediatr Adolesc Gynecol 2011;24:223-7.

3. Azziz R, Woods KS, Reyna R, et al. The prevalence and features of the polycystic ovary syndrome in an unselected population. J Clin Endocrinol Metab 2004;89:2745-9.

4. Franks S, Gharani N, McCarthy M. Candidate genes in polycystic ovary syndrome. Hum Reprod Update 2001;7:405-10.

5. Elsenbruch S, Hahn S, Kowalsky D, et al. Quality of life, psychosocial well- being, and sexual satisfaction in women with polycystic ovary syndrome. J Clin Endocrinol Metab 2003;88:5801-7.

6. Eshre TR, Group A-SPCW. Revised 2003 consensus on diagnostic criteria and long-term health risks related to polycystic ovary syndrome. Fertil Steril 2004;81:19-25.

7. Gowri BV, Chandravathi PL, Sindhu PS, Naidu KS. Correlation of skin changes with hormonal changes in polycystic ovarian syndrome: A crosssectional study clinical study. Indian J Dermatol 2015;60:419.

8. Clark C, Shalita A, Lowenstein E, et al. The dermatologic manifestation of hyperandrogenism: A retrospective chart review: P1131. J Am Acad Dermatol 2011;64.

9. Hong JS, Kwon HH, Park SY, et al. Cutaneous manifestations of the subtypes of polycystic ovary syndrome in Korean patients. J Eur Acad Dermatol Venereol 2015;29:42-7.

10. Feng J, Guo Y, Ma L, et al. Prevalence of dermatologic manifestations and metabolic biomarkers in women with polycystic ovary syndrome in north China. J Cosmet Dermatol 2018;17: 511-7.

11. Archer JS, Chang RJ. Hirsutism and acne in polycystic ovary syndrome. Best Pract Res Clin Obstet Gynaecol 2004;18:737-54.

12. Khomami MB, Tehrani FR, Hashemi S, et al. Of PCOS symptoms, hirsutism has the most significant impact on the quality of life of Iranian women. PLoS One 2015; 10:e0123608.

13. Bunker CB, Newton JA, Kilborn J, et al. Most women with acne have polycystic ovaries. $\mathrm{Br} \mathrm{J}$ Dermatol 1989;121:675-80.

14. Lee AT, Zane LT. Dermatologic manifestations of polycystic ovary syndrome. Am J Clin Dermatol 2007;8:201-19.

15. Essah PA, Wickham III EP, Nunley JR, Nestler JE. Dermatology of androgenrelated disorders. Clin Dermatol 2006;24:289-98.

16. Williamson K, Gunn AJ, Johnson N, Milsom SR. The impact of ethnicity on the presentation of polycystic ovarian syndrome. Aust N Z J Obstet Gynaecol 2001;41:202-6.

17. Huang Z, Yong EL. Ethnic differences: Is there an Asian phenotype for polycystic ovarian syndrome? Best Pract Res Clin Obstet Gynaecol 2016;37:4655.

18. Hayashi N, Akamatsu H, Kawashima M, Group AS. Establishment of grading criteria for acne severity. J Dermatol 
2008;35:255-60.

19. Lumezi BG, Berisha VL, Pupovci HL, et al. Grading of hirsutism based on the Ferriman-Gallwey scoring system in Kosovar women. Adv Dermatol Allergol Dermatol Alergol 2018;35:631.

20. Gupta M, Mysore V. Classifications of patterned hair loss: a review. J Cutan Aesthetic Surg 2016;9:3.

21. Plewig G, Jansen T. Seborrheic dermatitis. Fitzpatrick's Dermatol Gen Med 1999;1:1482-9.

22. Phiske MM. An approach to acanthosis nigricans. Indian Dermatol Online J 2014;5:239.

23. Chaudhari AP, Mazumdar K, Mehta PD. Anxiety, depression, and quality of life in women with polycystic ovarian syndrome. Indian J Psychol Med 2018;40:239-46.

24. Singh A, Chaudhary RKP. Study of Cutaneous Manifestations of Polycystic Ovarian Syndrome. JMSCR 2017;5:21177-82.

25. Schmidt TH, Khanijow K, Cedars MI, et al. Cutaneous findings and systemic associations in women with polycystic ovary syndrome. JAMA Dermatol 2016;152:391-8.

26. Jain P, Jain S, Singh A, Goel S. Pattern of dermatologic manifestations in polycystic ovarian disease cases from a tertiary care hospital. Int $\mathrm{J} \mathrm{Adv} \mathrm{Med}$ 2018;5:197-201.

27. Yerram C, Rao GV, Kilaru KR. Study of cutaneous manifestations in patients with polycystic ovarian syndrome attending a tertiary care centre. Int J Res 2019;5:481.

28. Khunger N, Kumar C. A clinico-epidemiological study of adult acne: is it different from adolescent acne? Indian J Dermatol Venereol Leprol 2012;78:335.

29. Lumezi BG, Pupovci HL, Berisha VL, et al. Acne in hirsute women. Adv Dermatol Allergol Dermatol Alergol 2014;31:356.

30. Dreno B, Poli F. Epidemiology of acne. Dermatology 2003;206:7.

31. El Akawi Z, Abdel Latif Nemr N, Razzak A, Al Aboosi M. Factors believed by Jordanian acne patients to affect their acne condition. EMHJ-East Mediterr Health J 2006;12:840-6.

32. Kopera D, Wehr E, Obermayer-Pietsch B. Endocrinology of hirsutism. Int $\mathrm{J}$ Trichology 2010;2:30.

33. Nazir F, Tasleem H, Tasleem S, et al. Polycystic ovaries in adolescent girls from Rawalpindi. JPMA-J Pak Med Assoc 2011;61:960.

34. Gatee OB, Al Attia HM, Salama IA. Hirsutism in the United Arab Emirates: a hospital study. Postgrad Med J 1996;72:168-71.

35. Al-Ruhaily AD, Malabu UH, Sulimani RA. Hirsutism in Saudi females of reproductive age: a hospital-based study. Ann Saudi Med 2008;28:28-32.

36. Zreik RS, Nasrallah MP. The prevalence of endocrinopathies among Lebanese women presenting with hirsutism to an endocrine clinic. Leban Med J 2014;103:1-6.

37. Saxena P, Prakash A, Nigam A, Mishra A. Polycystic ovary syndrome: Is obesity a sine qua non? A clinical, hormonal, and metabolic assessment in relation to body mass index. Indian $\mathrm{J}$ Endocrinol Metab 2012;16:996.

38. Olsen EA. Disorders of hair growth: diagnosis and treatment. McGraw-Hill; 2003.

39. Hatch R, Rosenfield RL, Kim MH, Tredway D. Hirsutism: implications, etiology, and management. Am J Obstet Gynecol 1981;140:815-30.

40. Sachdeva S. Hirsutism: evaluation and treatment. Indian J Dermatol 2010;55:3.

41. Simpson NB, Barth JH. Hair patterns: hirsuties and baldness. Dis Hair Scalp 3rd Edn Oxf Blackewell Sci 1997;67122.

42. Birch MP, Messenger JF, Messenger AG. Hair density, hair diameter and the prevalence of female pattern hair loss. Br J Dermatol 2001;144:297-304.

43. Ozdemir S, Ozdemir M, Görkemli H, et al. Specific dermatologic features of the polycystic ovary syndrome and its association with biochemical markers of the metabolic syndrome and hyperandrogenism. Acta Obstet Gynecol Scand 2010;89:199.

44. Keen MA, Shah IH, Sheikh G. Cutaneous manifestations of polycystic ovary syndrome: A cross-sectional clinical study. Indian Dermatol Online J 2017;8:104.

45. Ramos PM, Miot HA. Female pattern hair loss: a clinical and pathophysiological review. Ann Bras Dermatol 2015;90:529-43.

46. Hud JA, Cohen JB, Wagner JM, Cruz $\mathrm{PD}$. Prevalence and significance of acanthosis nigricans in an adult obese population. Arch Dermatol 1992;128: 941-4.

47. Pasquali R, Antenucci D, Casimirri F, et al. Clinical and hormonal characteristics of obese amenorrheic hyperandrogenic women before and after weight loss. J Clin Endocrinol Metab 1989; 68:173-9.

48. Shivaprakash G, Basu A, Ashwin Kamath PS, et al. Acanthosis nigricansin PCOS patients and its relation with type 2 diabetes mellitus and body mass at a tertiary care hospital in southern India. J Clin Diagn Res JCDR 2013; 7:317.

49. Sharquie KE, Al-Bayatti A, Al-Bahar AJ, Al-Zaidi Q. Acanthosis nigricans as skin manifestation of polycystic ovaries syndrome in primary infertile females. 2004

50. Lim SS, Davies MJ, Norman RJ, Moran LJ. Overweight, obesity and central obesity in women with polycystic ovary syndrome: a systematic review and meta-analysis. Hum Reprod Update 2012;18:618-37.

51. Pasquali R. The endocrine impact of obesity in eumenorrheic women. Androg Excess Disord Women Phila PA Lippincott-Raven. 1997;455-61.

52. McCartney CR, Blank SK, Prendergast $\mathrm{KA}$, et al. Obesity and sex steroid changes across puberty: evidence for marked hyperandrogenemia in pre-and early pubertal obese girls. J Clin Endocrinol Metab 2007;92:430-6.

53. Day F, Karaderi T, Jones MR, et al. Large-scale genome-wide meta-analysis of polycystic ovary syndrome suggests shared genetic architecture for different diagnosis criteria. PLoS Genet 2018;14:e1007813.

54. Dumitrescu R, Mehedintu C, Briceag I, et al. The polycystic ovary syndrome: an update on metabolic and hormonal mechanisms. J Med Life 2015;8:142.

55. Franik G, Bizoń A, Włoch S, et al. Hormonal and metabolic aspects of acne vulgaris in women with polycystic ovary syndrome. Eur Rev Med Pharmacol Sci Internet 2018;4411-8.

56. Cela E, Robertson C, Rush K, et al. Prevalence of polycystic ovaries in women with androgenic alopecia. Eur J Endocrinol 2003;149:439-42.

57. Quinn M, Shinkai K, Pasch L, et al. Prevalence of androgenic alopecia in patients with polycystic ovary syndrome and characterization of associated clinical and biochemical features. Fertil Steril 2014;101:1129-34. 